\title{
O Cartório e a Caixa Registradora Sobre ANERKENNUNg E ÉCriture
}

\author{
Hilan Bensusan ${ }^{1}$
}

\begin{abstract}
RESUMO: O trabalho considera as relaçôes entre a escrita e o reconhecimento. Os esforços de Derrida começaram a mostrar que a distinção entre a oralidade e a escrita é filosoficamente importante - e que muitos problemas filosóficos são problemas da escrita. A partir dessa perspectiva, considero a distinção entre conotação e denotação e a ideia - abraçada por Mill e, mais recentemente, por teorias da denotação inspiradas em Kripke - de que a denotaçáo prescinde, em grande medida, de conotaçáo. A diferença entre conotação e denotação é então associada à diferença entre a oralidade e a escrita. Nesse contexto, o tema do reconhecimento aparece. O reconhecimento, tal como identificado em uma tradição kantiana, também tem nuances relativas à escrita e à oralidade e estas nuances são exploradas. As queixas de Lévinas com respeito ao reconhecimento são então exploradas e analisadas desde um ponto de vista gramatológico (isto é, um ponto de vista que dá atenção à escrita). O trabalho termina com algumas consideraçóes gerais sobre o reconhecimento, a escrita e a natureza dos encontros, mesmo em situaçōes em que o reconhecimento não tem um papel central.
\end{abstract}

PALAVRAS-CHAVE: Anerkennung. Escrita. Oralidade. Denotação. Conotação.

1. A convicção de que o esforço da filosofia se inscreve nas dinâmicas e nas constâncias da linguagem tomou várias formas, nas últimas décadas. Dissolver aporias, desfraldar sintomas, contemplar encruzilhadas por meio da linguagem - tais empreitadas compuseram os giros linguísticos. A linguagem passou a aparecer como um telescópio do mundo, ou um museu do pensamento sedimentado, ou como uma encenação do poder. E, no entanto,

\footnotetext{
${ }^{1}$ Hilan Bensusan pesquisa e ensina no Departamento de Filosofia da Universidade de Brasília. No último ano, foi professor e pesquisador convidado na Universidade de Paris 8 e na Universidade de Madras em Chennai. Nos últimos dois anos, publicou em periódicos como Acta Analytica, Speculations, International Journal of Philosophical Studies, Croatian Journal of Philosophy e Kriterion (UFMG). Nos últimos cinco anos, publicou, entre outros, os livros Excessos e Exceçóes (Idéias e Letras, 2008), Heráclito - Exercícios de Anarqueologia (Idéias e Letras, 2012) e Pacífico Sul, ou Teoria Geral da Referência (Companhia do Vento, 2012). E-mail: hilantra@gmail.com.
} 
a linguagem é ela mesma produzida, ela tem suas manivelas consertadas e tem também sua genealogia.

Uma atenção ao que compôe as engrenagens com as quais a linguagem provoca seus impactos - a composição gradual delas - levou a um outro giro, talvez um giro dentro dos giros, talvez um giro para acabar com todos os giros. Trata-se da atenção à escrita, à escritura, ao grafismo que subordina a voz em sua oposição à oralidade. Vou chamar esse giro de giro gramatológico. Gelb entendia a gramatologia como o estudo das escritas (letras, gramma) - ele se interessava pela situação em que se apresentavam significantes não interpretados. Derrida apontou para a conexão entre a escrita e o alcance da lei. A escrita introduziu, e esta é a dimensão do giro gramatológico que vai me interessar, um possante equipamento de registro. Essa introdução afetou não apenas o acesso e o armazenamento dos eventos no mundo - o que se seguiria talvez de uma visão agostiniana da escrita, correlata da visão agostiniana da linguagem que Wittgenstein descreve, nas primeiras seções das Investigaçôes Filosóficas - mas introduziu outros elementos à ontologia. Derrida entende que a introdução da escrita foi um processo que mudou a natureza da linguagem e do que ela faz ao seu redor. Ele escreve, logo no início da Da Gramatologia:

[...] tudo acontece como se - deixando de designar uma forma particular, derivada, auxiliar de linguagem em geral (entendida como comunicaçáo, relaçãoo, expressão, significação, constituiçẫo do sentido ou do pensamento etc.), deixando de designar a película exterior, o duplo inconsistente de um significado maior, o significante do significante - o conceito de escritura começava a ultrapassar a extensão da linguagem. [...] A secundariedade, que se acreditava poder reservar à escrita, afeta todo significado em geral, afeta-o desde sempre, isto é desde o início do jogo. [...] Não é por acaso que este transbordamento sobrevém no momento em que a extensão do conceito de linguagem apaga todos os seus limites. (1967/2008, p. 8).

A escrita introduziu um elemento de ruptura com a localidade, que torna possível que um escrito distante (um ofício, um despacho, as letras miúdas de um contrato, um tratado) atue sobre um contexto sem estar em suas cercanias imediatas. A escrita, por exemplo, torna possível que a memória ganhe uma dimensão para além das lembranças das pessoas em cada contexto. Atentar para a escrita é, entre outras coisas, atentar para o registro.

Deleuze e Guattari, no terceiro capítulo do Anti-Édipo, associam a introdução da escrita à introdução do despotismo. $\mathrm{O}$ equipamento de 
registro que é o texto constitui o cerne de uma embocadura de todos os fluxos produtivos que eles chamam de máquina territorial despótica. Podemos chamar também, já que se trata disso, de caixa registradora despótica - em oposição àquela que é a superfície da terra, o registro que fica no chão, no local mesmo onde as coisas acontecem. A escrita surge como uma espécie de doma dos grafismos, uma doma em que de alguma maneira a voz assume o controle sobre as marcas, os resíduos que são marcados na terra (ou nos corpos). Com a escrita, ocorre assim uma

[...] subordinaçáo do grafismo à voz [que] induz uma voz fictícia das alturas que [...] já não se exprime a não ser pelos signos de escrita que ela emite (revelação). [...] Talvez comece aí a questão "o que isto quer dizer", assim como os problemas de exegese começam a prevalecer sobre os do uso e da eficácia. O que ele quis dizer, o imperador, o deus? Em vez de segmentos de cadeia sempre destacáveis, há um objeto destacado do qual depende toda a cadeia; em vez de um grafismo plurívoco, diretamente sobre o real, há uma biunivocização que forma o transcendente do qual sai uma linearidade; em vez de signos não-significantes que compõem as redes de uma cadeia territorial, há um significante despótico do qual escorrem uniformemente todos os signos num fluxo desterritorializado de escrita. (1972/2010, p. 272-273).

O déspota atinge distâncias pela palavra escrita, já que a distribuição de significantes permite que se passem coisas que são maquinadas pelo registro. $\mathrm{O}$ registro não apenas torna possível, mas coíbe, impele, modela. O registro tem uma agência, ele agencia, agrega a distância, por exemplo, corpos e nomes, nomes e filiações, nomes e funções, corpos e compromissos (não basta para o divórcio tirar a aliança). Esse agenciamento passa pelo escriba, pelo tabelião; a escrita produz um enorme cartório, uma rede de reconhecimentos de firmas. O cartório reconhece em Jocasta a mãe de Édipo - a caixa registradora procede a esse reconhecimento. Assim, destacam Deleuze e Guattari (e Derrida), o incesto (proibido) se torna possível. É possível que Édipo não saiba que Jocasta é sua mãe - e, ainda assim, ela o seja.

É justamente a questão do reconhecimento que me interessa analisar à luz do giro gramatológico. Os arquivos não são apenas repositórios de potenciais Anerkennungen, eles guardam uma capacidade de agir no reconhecimento, de proceder a um efeito de patrulha. A presença dos cartórios - sua sombra na qual perambulamos - transforma a cena dos nossos atos de reconhecimento. Fazemos coisas com cartórios. 
2. A fricção entre conotação e denotação aparece de maneira exemplar nos nomes próprios. A velha tese de Mill (1882, p. 29-94) é que os nomes são etiquetas, têm como que dutos diretos com seus denotata. A conotação não é invocada, não cumpre nenhum papel de transmissão. Ou seja, quem usa o nome denota mesmo em completa inocência do que o nome conota. Nem é preciso saber nada sobre o nome - em particular, não é preciso ter a capacidade de associar o nome a alguma descrição (ou a alguma descrição adequada). Não é quem usa o nome que determina o que está sendo nomeado, não é quem usa o nome que sabe o caminho do nome à denotação. Não é o usuário do nome o guardião do elo entre o nome e o que é nomeado - esse elo não está na cabeça de quem usa o nome. Não é o quem usa o nome que registra a conexão. Dito ainda de outra maneira, a cognição de quem usa o nome é prescindível, mesmo irrelevante para o bom funcionamento da etiqueta. A denotação, assim, funciona de modo independente do que é sabido, pressentido ou de alguma forma tratado (por exemplo, acquainted). E é alheia à conotação.

Um nome, assim, pode em alguma medida apontar para alguma coisa mesmo que não queiramos. E se não é o usuário do nome que faz o registro do denotata correspondente - por exemplo, mantendo uma matriz de descriçóes que precisaria ser satisfeita para que a denotação ocorra - alguma outra instância haverá de atuar como guardiã do elo entre nomes e denotaçóes. Uma analogia com o nominalismo quanto a propriedades (universais) talvez nos fizesse dizer que há um sedimento convencional que promove uma base para que se estenda o elo entre nomes e coisas. Porém, aqui há que se entender que tal sedimento passa ao largo da atenção de qualquer falante em particular - não requer que quem use um nome conheça a convenção. Uma etiqueta permite que a denotação passe por mãos (e bocas) que náo a compreendam, que não a decifrem. A etiqueta, decifrada ou não, é um grafismo que é significante - seu significado pode passar ao largo de quem faz uso dela.

Essa independência entre conotação e denotação foi atacada pela concepção de Bedeutung atrelada aos Sinne de Frege e, em grande medida, pela teoria das descriçóes de Russell. Tomemos primordialmente o caso dos nomes próprios (não-lógicos, não-genuínos) em Russell (1905). A estratégia é de entendê-los em termos de descriçôes a serem satisfeitas quando houver denotação. Os nomes próprios nomeariam através das descriçôes. Não há nada que satisfaça a descrição definida de ser o atual rei da França e, portanto, frases que envolvam tal descrição enunciam também que há um atual rei da França e, assim, são falsas. Russell exigia que fôssemos capazes de indicar as descriçóes 
correspondentes a cada nome próprio. Quine relaxou esse requisito - ele admitiu que podemos falar de socratizar ou de pegaseiar. Em geral compreendese, como Russell, que essas descriçóes compóem o significado (do falante) do nome próprio. Não há aqui um elo direto entre nome e objeto, a conotação é que faz a mediação - é apenas através da satisfação de descriçóes definidas que um nome próprio denota. A conotação faz, portanto, o serviço de ligação - não há denotação bem sucedida que não passe por ela. Analogamente, para Frege (1892), os Sinne constituem um elo funcional entre o nome e o que fica designado - o que na interpretação mais comum do estatuto dos Sinne significa dizer que há uma mediação cognitiva entre o termo e sua Bedeutung. Ou seja, o falante promove o registro do elo de denotação. A denotação, nesse esquema de privilégio da conotaçáo de Russell (e de Frege), acontece com o registro feito por quem faz uso do nome - se não é o falante o guardiáo da denotação, se ele não sabe do que está falando, se nada do que ele pensa sobre o que está falando é adequado, não há denotação. Nesse caso, não há um vínculo entre nome e portador que precisasse ser registrado longinquamente, já que o registro é cognitivo - e local. O usuário do termo é capaz de determinar a sua denotação - o trabalho de determinação da referência não é dividido, é concentrado. O nome, por sua vez, carrega ele mesmo uma conotaçáo conhecida pelo usuário (por exemplo, está associada a um nome uma descrição definida conhecida) que faz a ligação entre um termo e o que fica designado.

A sequência da história é descrita por Wettstein (2004) como uma revolução em filosofia da linguagem. Pode até parecer uma contrarrevolução, visto que alvejou os consensos fregeano e russelliano e pôs algumas ideias de Mill no centro das reflexôes sobre a linguagem e sobre o que ela promove. Porém, a revolução de que fala Wettstein abriu novas perspectivas para pensar a denotação. Ele sugere um motto que condensa estas perspectivas: contato linguístico sem contato cognitivo. Isto é, a linguagem faz coisas que a cognição do que estamos falando desconhece - a linguagem promove elos que passam ao largo do que conhece quem a usa. A imagem do registro local - através da conotaçáo associada a cada termo - foi atacada em diversas frentes por Donnellan, Kaplan e, mais proeminentemente, por Kripke (1980). A insistência de Kripke é a de que não há nada de necessário conectando um nome a uma descrição. Sócrates poderia nunca ter se metido com a filosofia e nem tomado cicuta. Jocasta poderia nunca ter parido Édipo. E, ainda assim, esses nomes seriam como uma etiqueta colada às pessoas. 
Aqui há muitos caminhos que podemos seguir - por exemplo, se nos perguntarmos se Édipo poderia náo ser filho de Jocasta. No entanto, importa que, com a introdução de considerações modais, o registro do elo entre nome e coisa parece ser outra vez independente de qualquer cognição. A linguagem ela mesma faz o serviço. Ela promove a ação a distância, alheia ao que pensamos ou deixamos de pensar dos nomes. Tal ação a distância ocorre porque há uma caixa registradora, uma projeção das palavras para além do falante e do ouvido. As palavras ressoam em um éter de ofícios, enciclopédias, portarias, veredictos e coleçóes. Um grupo de falantes pode manter um registro de seus termos, mas esse registro é negociado com a caixa registradora (despótica) que guarda elos de denotação. Quer dizer, a escrita introduz elos denotativos alheios ao que sabe, quer ou convenciona um grupo de falantes - a linguagem ganha um espectro de langue que, ainda que não forneça as condiçóes suficientes e necessárias para a interpretação de toda emissão, assombra a parole. O contato linguístico do motto de Wettstein é uma base de código sobre o qual náo se pode senão sobrecodificar - convencionamos uma denotação local para Sócrates ou para Édipo, porém, ouvimos o eco dos elos denotativos prontos. Dizer "Jocasta" em um ambiente onde não haja registro local do elo denotativo remete a Jocasta (independente de se ela foi a mãe de Édipo) através dos registros que independem dos falantes e do que eles sabem sobre Jocasta.

Talvez as caixas registradoras também aqui se sobreponham - a cognição e o contato denotativo. Talvez os nomes às vezes apelem para o que sabemos sobre eles e às vezes para o que está registrado no aparato de registro que é a linguagem. A dificuldade em lidar com a fricção entre conotação e denotação talvez esteja ecoando a convivência da escrita com um subterrâneo de oralidade; estamos às voltas com uma superposição de procedimentos, de regimes, de linhas de transmissão. A oralidade talvez seja o espaço das negociações e, com ela, da satisfação das descriçóes. Em certo sentido, as descriçôes estão próximas das questóes sobre a serventia das coisas - a serventia, e não o significado. Por isso, as conotaçóes são frequentemente relacionais e ocupam um espaço intensional - as intensôes, como os Sinne tais como os interpreta Dummett, são procedimentos para chegarmos a um objeto. Elas não são etiquetas; mas, justamente, as etiquetas são despóticas. É certo que já há rudimentos de ação a distância nos grafismos, portanto, elementos inegociáveis na oralidade. No entanto, na escrita, a negociação se torna irrelevante e, no máximo acessória, não é preciso mais do que qualquer contato linguístico. Talvez a variedade do uso dos nomes próprios seja um reflexo da duplicidade dos regimes de linguagem: a voz colonizada pela escrita e a voz que se articula alheia aos registros. A 
escrita se sobrepóe à oralidade justamente etiquetando coisas para além de suas cercanias - o déspota, como o Deus onisciente, precisa marcar seus súditos com independência do que eles façam (ou da descrição definida que eles estejam a satisfazer) - mas a escrita não substitui os mecanismos da oralidade.

A escrita reconhece os sujeitos, registra-os. Ela introduz os ofícios, os éditos, os textos autoritativos. E uma instância de ostensão sempre pressuposta: a etiqueta. A linguagem escrita, assim como a terra como dispositivo de registro, faz um inventário dos objetos de discurso: sobre o que está escrito alhures falamos. Aprendemos a ver as coisas a partir do inventário da escrita por isso, as metafísicas da era da escrita são metafísicas expressas na gramática (os objetos, as propriedades, os eventos etc.) - e com base no inventário da escrita transita o pensamento que prescinde do contato cognitivo, já que há um registro que faz a transmissáo entre nome e objeto. $\mathrm{O}$ que é o contato linguístico? É o contato por meio dos registros da escrita - um campo social que inventaria e cujo inventário intermedeia o que mencionamos e o que designamos. Aquilo que Deleuze e Guattari chamam de socius, o dispositivo de registro que é também um véu de reconhecimento que se estende sobre o que podemos designar. Sobra a conotação, contudo, ela tem que se articular dentro dos parâmetros desse véu registrador que pré-reconhece as coisas, que promove, independentemente de qualquer cogniçáo, um elo entre o que fica falado e aquilo a que correspondem as etiquetas.

3. Nos primeiros parágrafos de Autrement que l'être, Lévinas (1978) apresenta algumas das suas consideraçóes mais pungentes contra a ideia de que a liberdade do outro possa ser menos que imposta a nós. Ele entende que não há alteridade, se precisarmos derivar de nossa liberdade a liberdade alheia. Aquilo que depende da nossa agência, da nossa eleição ou da nossa subjetividade não pode ser senão o mesmo. Lévinas procura exorcizar o elo entre reconhecimento e alteridade. $\mathrm{O}$ sujeito, ele pensa, não pode ser instituído por um ato de reconhecimento, uma vez que isso pressuporia que a liberdade alheia depende da minha. De um ato de liberdade só pode decorrer aquilo que se subordina a ela, não aquilo que é diferente dela. O reconhecimento requer uma impressão, um decalque sobre alguém, institui o sujeito, sobrecodifica um nome sobre seu registro corporal - ele faz um batismo. Dar nomes aos bois é já instituir o mesmo sobre eles, fazer com que eles sejam portadores sempre do mesmo nome. A queixa de Lévinas é de que reconhecer é imprimir o mesmo e, assim, se o ato de reconhecimento funda o sujeito, o sujeito assim 
instaurado (assujeitado) não pode ser mais do que o mesmo. O outro só pode ser imposto a nós. Diante do outro, eu posso apenas me abrir a sua imposição, apenas ser passivo a sua liberdade alheia. Posicionar-se em uma passividade. O reconhecimento que Lévinas rejeita é aquele que faz com que o outro seja registrado pelo sujeito - um sujeito não pode instituir outro; se esta é a manobra do reconhecimento, ela tem que ser rejeitada. Assim, ou o reconhecimento é um ato de pura receptividade (de abertura a uma passividade, de aceitação de uma imposição), ou não pode mais do que instituir o mesmo.

Eis a pungência do dilema de Lévinas. Reconhecer, ou mesmo conhecer, se não passar de um exercício de incorporação do outro pelo mesmo, é um ato de colonização, um ato violento de apropriação e de assujeitamento. Ou há a possibilidade de um genuíno encontro, ou náo há sujeitos a serem encontrados. É certo que aqui há nuances importantes, sobretudo quando consideramos um cenário diferente do de Lévinas, que imaginava o encontro como um campo de tensão com nunca mais do que dois polos. Não há o espaço para mais do que o eu e a terceira pessoa, já que os encontros são pensados como imediados. Porém, o registro do reconhecimento, ele suspeita, ou é independente de nós ou é um registro do mesmo.

Em Giving an Account of Oneself, Butler (2005) procura moderar o apelo de exterioridade que o rosto do outro evoca para Lévinas. Ela nos faz tomar em consideração o conceito de rosto para apontar que um sujeito não é apenas interpessoal, náo é instaurado pela alteridade de um rosto como o nosso, a menos que já seja possível distinguir (ou seja, reconhecer) o que é um rosto. A dimensão de articulação social da aplicação de um conceito como rosto é o que inscreve o sujeito diante da imposição da alteridade. Pelo menos um ato de reconhecimento - digamos, das normas sociais que regulam a aplicação da noção de rosto - tem que ser levado a cabo para um sujeito topar com outro.

A observação de Butler tem alguns precedentes na tortuosa recepção da suspeita de Lévinas de que há uma dimensão central de violência no pensamento ontológico. Lévinas enxerga um caminho de saída pra o pensamento violento nos subsídios que nos podem dar os subterrâneos dos atos de reconhecimento. Derrida, já em Violence et Métaphysique (1962?), reagiu à suspeita de Lévinas, encaminhando-a para um tratamento temperado pelo giro gramatológico: a suspeita de Lévinas se acoplaria a outra suspeita, a de que há um grau de violência suposto e determinante na instauração do pensamento na era da escrita, inclusive na instauraçáo do pensamento não-violento. A violência da 
inscrição de conceitos em nosso pensamento - aquela violência que Brandom (1994) atribui à revolução copernicana de Kant, que ele formula como "[...] realizing that concepts have a grip on us" ${ }^{2}$ - é uma violência transcendental que torna possível todo ato de não-violência empírica. Há uma medida da violência da inscrição de conceitos no pensamento que é própria da escrita: próprio daquilo que não é local, da ação a distância sobre o pensamento. De todo modo, o ato de pensar, tal como nós o concebemos, é um ato de violência, um ato que instaura uma violência constitutiva sobre as coisas e que torna possível momentos de não-violência no varejo. Tal como com o déspota, instaura-se o terror, para que possa haver segurança.

Acho que importa lembrar que Lévinas era cuidadoso em não insinuar que seria preciso abandonar a perspectiva instaurada por Kant acerca do pensamento e do conhecimento, em favor da aceitação de que podemos ter conteúdos de pensamento que são puramente recebidos de nossos sentidos sem qualquer intervenção de capacidades conceituais. Não é que sua crítica à violência ontológica seja um convite a uma epistemologia empirista. É antes um convite a submeter o pensamento à força da exterioridade de uma alteridade. $\mathrm{O}$ problema não é a inscrição de um pensamento condicionado pelo mesmo em nós, o problema é antes a alteridade poder ser genuinamente presente em cada encontro. A observaçáo de Butler, assim como a de Derrida, deve, portanto, ser entendida assim: não é a epistemologia da alteridade que requer a inscrição do outro já em um ato de reconhecimento do sujeito, mas a existência mesma da alteridade que precisa estar registrada antes de qualquer contato interpessoal. Há um rosto antes de encontrarmos o rosto, ele não emerge do encontro. Ou seja, antes do registro do rosto do outro por um reconhecimento interpessoal, há que haver uma sançáo alhures que reconheça o rosto como um rosto. Uma inscrição. Um registro. Ninguém precisa reconhecer um rosto para que ele seja um rosto, mas é preciso que ele esteja registrado como tal, para que possa ser encontrado.

$\mathrm{O}$ rosto do outro tem que estar inventariado. Eis a dimensão do reconhecimento para o qual Derrida, o gramatólogo, aponta: a inscrição dos conceitos sobre o pensamento é condição para o pensamento. Nenhum encontro cria sujeitos (ou rostos) ex nihilo, eles estão presentes no socius que é o que permite o contato (não-cognitivo, no sentido de não-recognitivo) com um rosto como sendo rosto do outro. O reconhecimento é um registro; registro no rosto, registro na écriture. Lévinas se interessa pelo que fazemos nos encontros, não

${ }^{2}$ Dar-se conta de que os conceitos nos têm em suas mãos (minha tradução). 
importa a pré-história deles. Todavia, Butler e Derrida enfatizam a pré-história violenta, mesmo dos encontros náo-violentos. Um reconhecimento que tem que estar pronto mesmo antes que a polícia interpele. O pré-reconhecimento é esse dispositivo do déspota. Lévinas não aponta para a possibilidade de refazer a préhistória, mas para o que compomos com ela. Já há a escrita, e já estão inscritos no pensamento os tipos de coisa que podem ser reconhecidos. Entretanto, podemos, ele insinua, fazer outras coisas com cartórios.

4. Paul Auster, em City of Glass (1985), a primeira parte de New York Trilogy, acompanha os movimentos de Quinn, que foi contratado para seguir os passos de Stillman pelas ruas de Nova Iorque. Quinn se pergunta aonde vai Stillman - onde ele para, por que ele vai de um endereço a outro, o que ele faz em cada lugar, o que o move pelas ruas da cidade. Quinn se pergunta pela utilidade, pela função e pela eficiência dos itinerários de Stillman. Depois de segui-lo por algumas manhãs, registrando sempre por onde ele passava em um caderno, Quinn não tinha ideia do que estava fazendo Stillman pelas ruas. As vagâncias de Stillman pareciam despropositadas. Quinn então desenha em um papel as trajetórias do homem que está espionando a cada dia. Lentamente, ele se dá conta de que os passos de Stillman desenhavam significantes - e, assim, invocavam a pergunta: "O que isso quer dizer?" Não eram caminhadas em busca de alguma coisa pela cidade, eram escrituras que compunham uma expressão, letra por letra: THE TOWER OF BABEL. É certo que, depois da queda da torre de Babel, as pessoas já não entendiam o que as outras falavam, sabiam que havia ali significantes, mas não interpretavam o significado. Passa a ser possível a situação de uma interpretação radical, já que Babel fez descolar os significantes dos significados - em um primeiro movimento em direção à escrita despótica, que carrega uma autoridade independente do seu significado (a autoridade vem de quem assina, do carimbo, do papel timbrado). Quinn deixou de procurar o registro dos passos de Stillman na terra e nas ruas sobre a terra, para procurar o que estava registrado nas letras que ele desenhava. Stillman, e seus passos, estão desterritorializados, não importa a terra onde ele escreva suas letras, ele poderia estar escrevendo-as pelas ruas de qualquer outra cidade. Quinn agora tem que trabalhar sobre dois registros: o equipamento urbano da cidade (as ruas da cidade) e o alfabeto (nas ruas da cidade).

A escrita, em contraste com a oralidade, separa o significante do sítio onde a mensagem é produzida. O lócus de transmissão requer um socius que Stillman supóe, neste caso, que será compartilhado por Quinn (ou por qualquer 
outro decodificador dos significantes registrados em suas caminhadas). Eventualmente, determinado o registro apropriado, Stillman náo pode mais ir a um café em Nova Iorque sem escrever uma letra. O trabalho da escrita é o de significar para além do que é intencionado. $\mathrm{O}$ socius passa a registrar tudo. Os socii não se substituem, eles se sobrepõem, eles se sobrecodificam. Não há apenas Stillman, as ruas, as lojas, as esquinas e os becos de Nova Iorque, há também o alfabeto que permite reconhecer as letras de BABEL. Não há só os falantes, os ouvintes, os objetos tratados, há também a caixa registradora que registra contatos linguísticos mesmo despercebidos.

As caixas registradoras sobrepostas geram a estereoscopia que produz efeitos da fricção entre conotação e denotação. Expressôes passam a poder denotar alguma coisa a distância, mesmo usando, por exemplo, descriçóes definidas. A capacidade denotacional extravasa a circunstância da fala. Nos contratos e registros dos seguros de vida dos trabalhadores em benefício de suas empresas empregadoras nos Estados Unidos, antes da crise de 2007, aparecia, segundo conta Michael Moore em seu filme Capitalism, a Love Story, a expressão dead peasant, que fazia referência ao trabalhador morto. Na maioria dos casos, o trabalhador não era um camponês, mas descriçôes definidas como the respective dead peasant o denotavam - associando a ele um caráter conotativo depreciativo. A denotação da expressão fica fixada pelos seus usos nos documentos escritos, e passa a funcionar como uma etiqueta em que as propriedades de quem fica sendo denotado não têm nenhuma importância. Não importa como é possível saber o que é significado, importa que ele esteja circulando pelo socius, que ele esteja, de algum modo, no texto escrito - associado, sempre, com os procedimentos e dispositivos que compóem a política da exegese do texto (as instâncias de conferência, os tribunais, as escolas etc.).

A escrita, como a caminhada cheia de significantes de Stillman, recoloca a questão acerca do que há - não se trata apenas do que há sobre a terra, mas também do que há nos textos. Para Quinn, não há apenas cafés e becos em Nova Iorque, há também letras, palavras e seus significados. Com o advento do socius da escrita, importa o que é reconhecido pelos atos, pelas atas, pelos ofícios e também pelos manuais, pelas enciclopédias. O reconhecimento é uma prefiguração das coisas. $\mathrm{O}$ registro na terra é um critério de ontologia, o que há pelos corpos das coisas. A prefiguração na escrita é um outro critério: nele se produz contratos, acordos, posiçôes, textos sagrados, éditos, livros seminais, relatórios e tudo o que é reconhecido neles, como em um véu de 
prefiguração sobre o mundo. Reconhecer é registrar - e há vários registros, vários reconhecimentos.

5. Afinal, o que o giro gramatológico pode aportar para a questáo do reconhecimento? $\mathrm{O}$ registro duplo nos levou a dois esquemas de reconhecimento sobrepostos. O esquema da inscrição funda um regime em que o reconhecimento precede o encontro. $\mathrm{O}$ esquema da oralidade é também o esquema em que o que se passa se passa localmente. E localmente se passam os encontros - sobre a terra, já que os encontros são registrados no corpo dos sentidos. E, certamente, há muitos efeitos da sobreposição de esquemas - mencionei a friç̧ão entre conotação e denotação, porém, há também, por exemplo, os nossos encontros com os éditos, com os ofícios, com as enciclopédias e, é claro, com as vagâncias da interpretaçáo. $\mathrm{O}$ reconhecimento - como associado ao registro - tem passado e tem presente, e essas dimensóes apontam para esquemas distintos sobrepostos. A escrita tem uma vocação para o passado.

Voltemos à questão de Lévinas sobre a necessidade de passividade diante do outro. Ele quer rejeitar que possa haver açôes (de reconhecimento) por parte de quem se encontra diante do rosto do outro. Não há nada que possa conceder liberdade ao outro - ainda que a escrita de um édito possa ter um valor de reconhecimento, esse valor não pode executar todo ato performativo de dispor de um outro (livre). O encontro com o outro deve estar em um âmbito de abertura no seguinte sentido: o outro náo pode caber por completo em uma inscrição qualquer. A dimensão do encontro é cósmica, é a dimensão do que não está registrado em antecipação. Lévinas parece insinuar que, em um encontro, há uma dimensão que não pode ser passado. $\mathrm{O}$ presente, em contraste, tem o elemento de passividade daquilo que ainda não está pronto; há um elemento ali que faz com que o registro no presente não lhe possa fazer justiça - porque é um ato de registrar - e o registro no passado produz a presença da antecipação. Nessa dimensão do encontro presente, há um elemento de produção que não se consuma em registro, um elemento que precede à atualização (nesse caso, quase que o mesmo que o registro) e, portanto, está em um subterrâneo de tudo aquilo que termina por ser registrado.

Há algumas semelhanças entre o encontro pensado como incapturável pelo registro e a noção de aliança demoníaca em Viveiros de Castro (por exemplo, em Métaphysiques Cannibales, 2009). A aliança demoníaca não pode contar com o passado, é a corda vibrante bipolar, como é o caso entre uma 
pessoa que caminha na mata e um jaguar. Ali há uma dimensão de passividade e há uma pressão por uma negociação intensiva, já que não há contratos, não há acordos, não vale o escrito (e nem vale o valor do fluxo de capital). A aliança demoníaca, para Viveiros, contrasta com a filiação (extensiva) de onde sai a genealogia, o parentesco e de onde se projeta um estado (uma nação, uma etnia). Deleuze e Guattari pensam que a filiação prefigura o despotismo e, com ele, a escrita. A aliança demoníaca é o que pode se contrapor à filiação (e, segundo Viveiros, o faz nas sociedades contra o estado - na expressáo de Clastres - que ele encontra no baixo Amazonas). A filiação também parece ter sua proximidade com o reconhecimento, com o reconhecimento que prefigura. A negociação intensiva parece estar em contraste com ele - atividade, porém, atividade cercada de passividade. $\mathrm{O}$ reconhecimento, que contém as marcas da humanidade ou que possibilita que a humanidade se espelhe nele, talvez seja aquilo que nos é permitido fazer com os encontros. E a escrita talvez tenha deixado marcas de terror e despotismo nele.

Gostaria de concluir sugerindo brevemente uma alternativa na direção de subtrair da Anerkennung os elementos que a fazem humana, demasiado humana. Podemos encontrar no reconhecimento elementos de um acordo mútuo entre um elemento chancelado pela autoridade e uma autoridade reforçada. Trata-se de um encontro, mas de um encontro com uma medida importante de antecipação - um encontro sob um registro. $\mathrm{O}$ reconhecimento é uma espécie de aliança em que uma certa matriz de poderes é negociada uma aliança entre outras. $\mathrm{Na}$ aliança demoníaca, tal como descreve Viveiros de Castro, uma negociação de poderes permite algum ganho não antecipado. Alianças se estendem para além do escopo dos registros promovidos por algum socius. Podemos aludir a alianças entre nós e o jaguar na mata, mas também entre nós e a onça que chega à vila, entre a onça e um objeto de plástico, entre o objeto de plástico e o rio. Em cada um desses casos, diferentes redistribuiçóes de poderes e capacidades têm lugar. As práticas de reconhecimento são uma espécie de processo de constituição de alianças. Já estas últimas se estendem para além dos pactos, dos contratos, das promessas. Há alianças para além do reconhecimento, no meio das teias de reconhecimento, articuladas por reconhecimentos. Talvez sejam elas que individuem, elas que promovem diferenças e indiferenças. $\mathrm{O}$ reconhecimento não é mais que uma forma de aliança; e muitas delas não assinam contratos, não respeitam fronteiras, não obedecem a instâncias legais - são encontros não antecipados. Há assim uma dimensão nessas alianças que se impóem a nós como alteridades. Nem só de 
antecipaçôes sobrevivem as alianças. Os déspotas também são infectados por vírus e dizem que a melhor defesa da Amazônia é o mosquito da malária. ${ }^{3}$

BENSUSAN, Hilan. The registrar and the register: on Anerkennung and Écriture. Trans/ Form/Ação, Marília, v. 35, n. 3, p. 97-112, Set./Dez., 2012.

\begin{abstract}
This work examines the connections between writing and recognition. Derrida's work shows that the distinction between oral and written forms of language is of philosophical importance, and that many philosophical problems have to do with writing. Within this framework I consider the philosophically charged distinction between connotation and denotation, specifically, the idea put forward by Mill and endorsed more recently by theories of denotation inspired by the work of Kripke, that denotation may take place without resorting to connotation. I proceed to draw a relation between the distinction between connotation and denotation on the one hand, and that between oral and written language on the other. It is in this context that the idea of Anerkennung becomes important. Its nuances in written and oral forms are then elaborated. I analyze Lévinas critique of recognition from a grammatological perspective (i.e. from a perspective that focuses on written language). I conclude with some general remarks on recognition and writing, and on occasions where recognition can be deemed irrelevant.
\end{abstract}

KEYWORDS: Anerkennung. Writing. Orality. Denotation. Connotation.

\title{
REFERÊNCIAS
}

AUSTER, P. New York Trilogy. Nova Iorque: Sun \& Moon Press, 1985.

BUTLER, J. Giving an Account of Oneself. Nova Iorque: Fordham University Press, 2005.

BRANDOM, R. Making it Explicit: Reasoning, Representing and Discursive Commitment. Harvard University Press: Cambridge, Massachusetts, 1994.

DEleuzE, G.; GUATTARI, F. Anti-Oedipus: Capitalisme et Schizophrenia. Paris: Minuit, 1972/2010. Tradução brasileira de Le Plateaux. Paris, Minuit, 1980. Edição Brasileira: Anti-Édipo: Capitalismo e Esquizofrenia. Tradução de L. Orlandi. São Paulo: Editora 34, 2010.

DERRIDA, J. Violence et métaphysique: Essai sur la pensée d'Emmanuel Lévinas. Revue de métaphysique et de morale, 3-4, p. 322-354, 1964.

\footnotetext{
${ }^{3}$ Cf. "O mosquito da malária" do cantor e compositor amazonense Maca.
} 
DERRIDA, J. De la grammatologie. Paris: Seuil, 1967/2008. Edição brasileira: Da Gramatologia. Tradução de Antonio Ramos Rosa. São Paulo: Perspectiva, 2008.

FREGE, G. Über Sinn und Bedeutung. Zeitschrift für Philosophie und philosophische Kritik, 100, p. 25-50, 1892.

KRIPKE, S. Naming and Necessity, Oxford; Blackwell, 1980.

LÉVINAS, E. Autrement qu'être (ou au-delà de l'essence), Paris: Kluwer - Biblio, 1978.

MILL, J. S. A System of Logic, Nova Iorque: Harper \& Brothers, 1882.

RUSSELL, B. On denoting. Mind, 14(56), p. 479-493, 1905.

VIVEIROS DE CASTRO, E. Métaphysiques Cannibales. Paris: PUF, 2009.

WeTTSTEIN, H. The Magic Prism, Oxford: Oxford University Press, 2004.

Recebido em: 04.01.2012

Aceito em: 19.03.2012 
BENSUSAN, $H$. 